\title{
Pattern of Antibiotics Use for Prophylaxis and Treatment among Patients Who Undergone Major Surgery at Nekemte Referral Hospital, West Ethiopia
}

Tasissa Ayela Wokuma ${ }^{1}$ and Mohammed Gebre Dedefo ${ }^{2^{*}}$

${ }^{1}$ Department of Pharmacy, Mettu University, Mettu, Oromia, Ethiopia

${ }^{2}$ Department of Pharmacy, Wollega University, Nekemte, Oromia, Ethiopia

\begin{abstract}
Background: Appropriate use of antimicrobial agents is vitally important from clinical perspectives and is essential if the usefulness of antibiotic is to be preserved and the further spread of resistance is to be limited. Antibiotics are one of the pillars of modern medical care and play a major role both in prophylaxis and treatment of infectious diseases. However, their misuse is a worldwide problem with the extent of the problem being greater in the developing countries.
\end{abstract}

Objective: To assess antibiotics use for prophylaxis and treatment among patients who undergone major surgery in Nekemte Referral Hospital.

Methods: A retrospective cross-sectional study was conducted on 228 medical records of patients who undergone major surgery at Nekemte Referral Hospital during February 2017 to February 2018. Stratified random sampling technique was used for this study. Data was collected by using a pre-tested structured questionnaire from March, 2018 to May, 2018 and then analyzed using statistical package for social science (SPSS) version 20.0 software.

Result: Out of 228 patients who undergone major surgery 177 patients were male and 51 patients were females. Based on age group classification $<20(21.1 \%)$ was mostly affected. The most common diagnosis was appendectomy $(32.9 \%)$ followed benign prostate hyperplasia $(20.2 \%)$. The most frequently prescribed antibiotics drugs was ceftriaxone $(52.88 \%)$, followed by Metronidazole $(29.58 \%)$ for treatment and for prophylaxis ceftriaxone $(71.96 \%)$ followed metronidazole $(17.56 \%)$. The most used class of drug for prophylaxis was cephalosporin $(72.45 \%)$ and Nitro imidazole (17.35\%); and for treatment cephalosporin $(56.81 \%)$ followed by Nitro imidazole $(29.58 \%)$.

Conclusion: Generally, this study indicated that underwent surgical procedures by majority of patients were appendectomy and benign prostate hyperplasia. Mostly prescribed antibiotics in the patients who undergone major surgery were ceftriaxone followed by Metronidazole. In general, this study result indicated some level of inappropriateness which high light need for intervention.

Keywords: Antibiotics; Major surgery; Resistance; Prophylaxis; Treatment; Ethiopia

\section{Introduction}

Antibiotics are one of the pillars of modern medical care and plays major role both in prophylaxis and treatment of infectious diseases. The issues of their availability, selection, and proper use are of critical importance to the global community. Antibiotic misuses are however, a worldwide problem with the extent of the problem being greater in the developing countries through their purchase (without prescription) in local pharmacies and drug stores, and through inappropriate prescribing habits and an over-Zealous desire to treat severe infections [1].

Prophylactic antibiotics are widely used in surgical procedures and account for substantial antibiotic use in many hospitals. The purpose of SAP is to reduce the prevalence of postoperative wound infection (about $5 \%$ of surgical cases overall) at or around the surgical site. By preventing surgical site infections, prophylactic antimicrobial agents have the potential to decrease patient morbidity and hospitalization costs for many surgical procedures that pose significant risk of infection. However, the benefits of prophylaxis are controversial, prophylaxis is not justified for some surgical procedures (e.g., urologic operations in patients with sterile urine). Consequently, the inappropriate or indiscriminate use of prophylactic antibiotics can increase the risk of drug toxicity, selection of resistant organisms, and costs [2].

Serious morbidity and mortalities are associated with post-operative wound infections. They have an enormous impact on patient's quality of life and contribute substantially to the financial cost of patient care. The use of preoperative antibiotics has become an essential component of the standard of care in virtually all surgical procedures, and has resulted in a reduced risk of the post-operative infection when sound and appropriate principles of prophylaxis are applied [3].

In 1960s it was reported that pathogens are present during surgery

*Corresponding author: Dedefo MG, Department of Pharmacy, Wollega University, Nekemte, Oromia, Ethiopia, Tel: +251912021296; E-mail: mohamedg@ wollegauniversity.edu.et

Received October 17, 2018; Accepted October 23, 2018; Published October 29 2018

Citation: Wokuma TA, Dedefo MG (2018) Pattern of Antibiotics Use for Prophylaxis and Treatment among Patients Who Undergone Major Surgery at Nekemte Referral Hospital, West Ethiopia. J Bioanal Biomed 10:108-113. doi:10.4172/1948593X.1000217

Copyright: @2018 Wokuma TA, et al. This is an open-access article distributed under the terms of the Creative Commons Attribution License, which permits unrestricted use, distribution, and reproduction in any medium, provided the original author and source are credited. 
Citation: Wokuma TA, Dedefo MG (2018) Pattern of Antibiotics Use for Prophylaxis and Treatment among Patients Who Undergone Major Surgery at Nekemte Referral Hospital, West Ethiopia. J Bioanal Biomed 10:108-113. doi:10.4172/1948-593X.1000217

regardless of how aseptic the surgery might appear. Moreover, the correlation between prophylactic antibiotics and post-operative would infections were demonstrated. Therefore, antibiotic prophylaxis now used in almost all surgical procedures, the preoperative administration of antibiotics because it can act at the time when the wound is potentially contaminated that the use of antibiotics after 3-4 hours of a bacterial incision is unsuitable [4].

Previous studies have demonstrated that antibiotics must be active against major anticipated pathogens and must have reached sufficient concentration in the tissue or body fluids at risk by the time of bacterial challenges. If prophylactic therapy is to be maximally effective in reducing the infection rate of potentially contaminated surgery. The need for continuing antibiotic prophylaxis of operation, however, has been uncertain [5].

Different studies had indicated that there is high proportion of inappropriate antibiotics use for patients who admitted at surgical ward and these studies have also suggested reasons for inappropriateness as an excessive duration of treatment, incorrect timing of administration, inadequate antibacterial spectrum of the drugs used, and unnecessary combination of two antibiotics [6-16].

The increase resistance fate of many important pathogens to currently most available antibiotic has been recognized as an important and potentially life threatening problem. This problem is promoted in part by irrational antibiotics prescribing is behavior and usage. Medically in appropriate, in effective and economically inefficient use of pharmaceuticals is common health care systems problem throughout the world especially in the developing comities [10].

This study aimed at identifying inappropriate use of antibiotics for prophylaxis and treatment at surgical ward which serve as a baseline data for health authority and policy maker and it helps in developing strategies or essential drug list guideline for rational use of drugs at the hospital level as well as for improvement of hospital service.

\section{Methods}

\section{Study setting}

The study was conducted in Nekemte referral hospital, Nekemte town, Eastern Wollega zone, Oromia regional state which is located at $331 \mathrm{~km}$ from west of Addis Ababa. NRH was established in 1932 (1924 E.C) by Swedish missionary. It has a different department and wards like outpatient department (OPD), medical wards, gynecology and obstetrics ward, pediatrics ward and surgical ward. It delivers diversified health services and clinics including the emergency services, eye clinic, dental clinic, mother and child health $(\mathrm{MCH})$, psychiatry clinic, laboratory, radiology, pharmacy, physiotherapy and follow up of chronic disease. The study was conducted from March 20/2018 to May $5 / 2018$.

\section{Study design}

Retrospective cross- sectional study on assessment of drug use was conducted using patients' medical card.

Source population: All medical records of patients, who undergone major surgery from February 2017-February 2018.

Study population: A medical record of Patients with antibiotics prescription in major surgery which get chance of selection.

\section{Eligibility criteria}

Inclusion criteria: All patients who undergone major surgery from

\section{February, 2017 to February, 2018 at NRH}

Exclusion criteria: Patient cards with incomplete information for the study.

Sample size: The minimum statistically required sample size was calculated by using the following formula.

$\mathrm{N}=\underline{\mathrm{Z} 2 \mathrm{P}(1-\mathrm{P})}$

$\mathrm{D}^{2}$

Where:

$\mathrm{N}=$ Sample size required

$\mathrm{P}=$ Prevalence rate of antibiotics

$\mathrm{Z}=$ The standard normal Confidence at interval of $95 \%=1.96$

$\mathrm{D}=$ The margin of sampling error tolerated

Since there is no prevalence rate for prescription pattern, $50 \%$ was taken to get maximum sample size with confidence interval of

95\% margin of error therefore, the sample size was:

$\mathrm{n}=(\underline{1.96 \%)} 20.5(0.5)=384$

(0.05) 2

Since the total number of patients who undergone major surgeries are less than 10,000 the following correctional formula was used.

$$
n_{f}=\frac{n}{1+\frac{n}{N}}
$$

Where: $\mathrm{n}=$ initial sample size which was 384

$\mathrm{nf}=$ desired sample size

$\mathrm{N}=$ population size 560 (total number of patients who who undergone major surgery at NRH from February 2017-February 2018)

Therefore, $n f=n /(1+n / N)=384 /(1+384 / 560)=228$.

Sampling technique: Stratified random sampling method was conducted to select more representative sample. There are seven therapeutic indication of major surgery in NRH during study period, to calculate sample allocated to each stratum proportionate allocation was used. Then a simple random sampling was done depending on the type of allocation.

Proportionate allocation:

$\mathrm{ni}=\frac{\mathrm{n}}{\mathrm{N}} * \mathrm{Ni}$

Where:

$\mathrm{ni}$ is sample size of the $\mathrm{i}^{\text {th }}$ stratum

$\mathrm{Ni}$ is population size of the $\mathrm{i}^{\text {th }}$ stratum

\section{Study variables}

Independent variables: Age, Sex, Diagnosis, residence, number of antibiotics used, duration of hospital stay.

Dependent variables: Appropriateness of antibiotic use.

Data collection procedure: Relevant information about each patient like demographic factors, type of diagnosis, medication history (antibiotics used for prophylaxis and treatment including 
Citation: Wokuma TA, Dedefo MG (2018) Pattern of Antibiotics Use for Prophylaxis and Treatment among Patients Who Undergone Major Surgery at Nekemte Referral Hospital, West Ethiopia. J Bioanal Biomed 10:108-113. doi:10.4172/1948-593X.1000217

other medication used), other comorbid conditions, durations of hospitalization stay and condition of discharge were recorded using well-structured data collection format through reviewing medical records of patients. Other supplementary information was obtained from register. Appropriateness of antibiotic use was checked by using the Ethiopian Standard Guidelines for general hospitals [17].

Data quality control: To maximize accuracy of this study, data collection format was validated with its objective and developed enough to assess the objective of the study. This data collection format was pre-tested on 5\% [18] of patient's cards from the same source population before starting actual data collection. Patient's cards which used for pre-testing is not used in study. In addition, regular checkup for completeness and consistency of the data was made on daily basis. To check the consistency, data were entered in two different SPSS programs (double method).

\section{Data analysis and presentation}

Data entry and analysis was carried out using statistical package for social science (SPSS) version 20.0. Descriptive statistics were used for statistical analysis. The result was analyzed and presented using tables and graphs. Data available was interpreted and discussed with the results of similar studies.

\section{Ethical consideration}

Ethical clearance was obtained from Wollega University, College of Health Sciences Ethical Review Committee. A formal letter was written to the NRH in order to get permission to conduct the study and Official permission was granted from the hospital administration. To ensure confidentiality, name and other identifiers of patients and prescribers were not recorded on the data abstraction formats.

\section{Result}

\section{Socio-demographic characteristics}

A total of 228 patients' medical records that undergone major surgery and took antibiotics drugs were analyzed. The majority of the patients were less than 20 years, 48 (21.1\%) and 21-30 years, 45 (19.7\%). But inappropriateness of antibiotics used for treatment was higher in age between 51-60 years and above 60 years. And also the prevalence of inappropriateness is higher in antibiotics used for treatment (43.4\%) than for prophylaxis $(27.6 \%)$ (Table 1$)$.

\section{Therapeutic indication}

Out of 228 patients who undergone major surgery at NRH from February 2017 to February 2018, the most frequently diagnosed disease for which antibiotic indicated were appendectomy 75 (32.9\%) followed by Benign prostate hyperplasia 46 (20.2\%) (Table 2 ).

\section{Total antibiotics used for surgical prophylaxis and treatment}

As shown below in the Table 3, the most commonly prescribed antibiotics for patients who undergone major surgery for both Prophylaxis and Treatment Were Ceftriaxone $71.96 \%$ and $52.88 \%$ respectively, followed by Metronidazole (Table 3).

\section{Prescribed antibiotic drug regimens (single/multiple drugs) for prophylaxis and treatments}

228 patients were treated with different regiment of antibiotics drugs. The numbers of patients who were treated with monotherapy for prophylaxis were $160(70.2 \%)$ and for the treatment were $85(37.3 \%)$.

\begin{tabular}{|c|c|c|c|c|}
\hline \multirow{2}{*}{ No. } & \multirow{2}{*}{$\begin{array}{l}\text { Socio-demographic } \\
\text { characteristics }\end{array}$} & \multirow{2}{*}{$\begin{array}{l}\text { Frequency } \\
\quad \mathrm{N}(\%)\end{array}$} & \multicolumn{2}{|c|}{$\begin{array}{c}\text { Inappropriateness of antibiotic } \\
\text { used }\end{array}$} \\
\hline & & & $\begin{array}{c}\text { For Prophylaxis } \\
\text { N (\%) }\end{array}$ & $\begin{array}{c}\text { For Treatment } \\
\quad \mathrm{N}(\%)\end{array}$ \\
\hline \multirow{8}{*}{1} & \multicolumn{4}{|c|}{ Age group (year) } \\
\hline & $<20$ & $48(21.1)$ & $11(22.9)$ & $20(41.7)$ \\
\hline & $21-30$ & 45 (19.7) & $11(24.4)$ & $17(37.8)$ \\
\hline & $31-40$ & 34 (14.9) & $8(23.5)$ & $13(38.2)$ \\
\hline & $41-50$ & $42(18.4)$ & $12(28.6)$ & $18(42.8)$ \\
\hline & $51-60$ & $28(12.3)$ & $10(35.7)$ & $16(57.1)$ \\
\hline & $>60$ & $31(13.6)$ & $11(35.5)$ & $15(48.4)$ \\
\hline & Total & $228(100)$ & $63(27.6)$ & $99(43.4)$ \\
\hline \multirow{3}{*}{2} & \multicolumn{4}{|c|}{ Sex } \\
\hline & Male & $177(77.6)$ & $48(27.1)$ & $79(44.6)$ \\
\hline & Female & $51(22.4)$ & $15(29.4)$ & $20(39.2)$ \\
\hline \multirow{3}{*}{3} & \multicolumn{4}{|c|}{ Residence } \\
\hline & Urban & $89(39.0)$ & $22(24.7)$ & $34(38.2)$ \\
\hline & Rural & $139(61.0)$ & $41(29.5)$ & $65(46.8)$ \\
\hline \multicolumn{5}{|c|}{$\mathrm{N}$ - is the number of patient } \\
\hline
\end{tabular}

Table 1: Socio-demographic characteristics cross tabulation with inappropriateness of antibiotic used for patients who undergone major surgery at surgical ward of NRH from February 2017 to February 2018 n=228.

\begin{tabular}{|c|c|c|}
\hline Diagnosis & Frequency & Percentage (\%) \\
\hline Appendectomy & 75 & 32.9 \\
\hline BPH & 46 & 20.2 \\
\hline LBO & 32 & 14 \\
\hline Inguinal hernia & 24 & 10.5 \\
\hline SBO & 23 & 10.1 \\
\hline GS & 16 & 7 \\
\hline Cholecystectomy & 12 & 5.3 \\
\hline Total & 228 & 100 \\
\hline
\end{tabular}

Table 2: Types of diagnosis of major surgery at NRH from February 2017 to February 2018.

\begin{tabular}{|c|c|c|}
\hline \multirow{2}{*}{ Drug name } & Prophylaxis & Treatment \\
\cline { 2 - 3 } & No of patients N (\%) & No of patients N (\%) \\
\hline Ceftriaxone & $213(71.96 \%)$ & $202(52.88 \%)$ \\
\hline Metronidazole & $52(17.56 \%)$ & $113(29.58 \%)$ \\
\hline Cloxacillin & $11(3.71 \%)$ & $14(3.66 \%)$ \\
\hline Ampicillin & $20(6.76 \%)$ & $21(5.5 \%)$ \\
\hline Gentamycin & 0 & $14(3.66 \%)$ \\
\hline Cephalexin & 0 & $15(3.93 \%)$ \\
\hline Norflaxacillin & 0 & $3(0.79 \%)$ \\
\hline Total & $296(100 \%)$ & $382(100 \%)$ \\
\hline
\end{tabular}

Table 3: Total antibiotics used for surgical prophylaxis and treatment at NRH for a patient who undergone major surgery from February 2017 to February 2018.

From antibiotic combinations, combinations of two drugs prescribed for prophylaxis were $68(29.80 \%)$, and for the treatment were 130 (57.00\%) patients (Figure 1).

\section{Appropriateness of antibiotics}

Appropriate antibiotics used for prophylaxis were 165 (72.37\%) and appropriate antibiotics used for treatment where 129 (56.58\%) (Table 4). 
Citation: Wokuma TA, Dedefo MG (2018) Pattern of Antibiotics Use for Prophylaxis and Treatment among Patients Who Undergone Major Surgery at Nekemte Referral Hospital, West Ethiopia. J Bioanal Biomed 10:108-113. doi:10.4172/1948-593X.1000217

\section{Single prescribed antibiotics}

As shown below in Table 5, the most frequently prescribed antibiotics are ceftriaxone; for prophylaxis $98.75 \%(\mathrm{~N}=158)$ and for treatment $96.5 \%(\mathrm{~N}=83)$ (Table 6).

\section{Combination of antibiotics used for prophylaxis and treatment}

According to the result in Table 6 below, antibiotics combination regimen used for prophylaxis was Ceftriaxone+Metronidazole (57.4\%), Metronidazole+Ampicillin (19.1\%), Ceftriaxone+cloxacillin (16.2\%), Ampicillin+Ceftriaxone (7.4\%).

For treatment; Ceftriaxone+Metronidazole (76.8\%), Metronidazole+Ampicillin (3.6\%), Ceftriaxone+cloxacillin (8\%), Ampicillin+Ceftriaxone (2.2\%), Ampicillin+Gentamicin+Cephalexi $\mathrm{n}(8 \%)$ and Ampicillin+Ceftriaxone+Metronidazole (1.45\%) (Table 6).

\section{Class of antibiotic prescribed}

This study indicate that most prescribed antibiotic classes were cephalosporin 213 (72.45\%), followed by nitro imidazole 51 (17.35\%) for prophylaxis and cephalosporin 217 (56.81\%), and nitro imidazole $113(24.26 \%)$ for treatment respectively (Table 7 ).

\section{Presence of other comorbid conditions and other medications} taken, duration of hospital stay and condition of discharge

As shown in the table below, $36.4 \%$ patients had other comorbid conditions and $32.9 \%$ patient have taken other medication in addition to antibiotics. Duration of Hospital stay was $<10$ days for $76.3 \%$

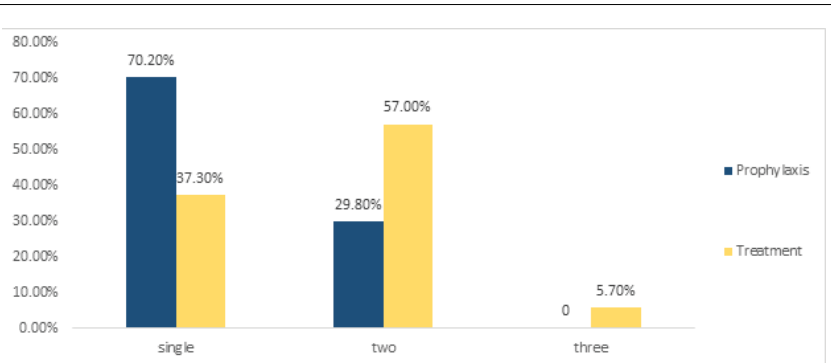

Figure 1: Prescribed antibiotic drugs regimen (single/multiple drugs) for prophylaxis and treatments at surgical ward of NRH from February 2017 to February 2018

\begin{tabular}{|c|c|c|c|c|}
\hline $\begin{array}{c}\text { Reason for } \\
\text { use }\end{array}$ & \multicolumn{2}{|c|}{ Appropriateness } & Frequency & $\begin{array}{c}\text { Percentage } \\
(\%)\end{array}$ \\
\hline \multirow{4}{*}{ Prophylaxis } & \multicolumn{2}{|c|}{ Appropriate } & 165 & 72.37 \\
\hline & \multirow{3}{*}{ Inappropriate } & inappropriate choice & 40 & 17.54 \\
\hline & & $\begin{array}{l}\text { unnecessary } \\
\text { combination }\end{array}$ & 23 & 10.09 \\
\hline & & Total & 63 & 27.63 \\
\hline \multirow{6}{*}{ Treatment } & \multicolumn{2}{|c|}{ Appropriate } & 129 & 56.58 \\
\hline & \multirow{5}{*}{ Inappropriate } & Excessive duration & 27 & 11.84 \\
\hline & & Short duration & 9 & 3.94 \\
\hline & & inappropriate choice & 45 & 19.74 \\
\hline & & $\begin{array}{l}\text { unnecessary } \\
\text { combination }\end{array}$ & 18 & 7.9 \\
\hline & & Total & 99 & 43.42 \\
\hline
\end{tabular}

Table 4: The appropriateness of antibiotic used for patients who undergone major surgery at NRH from February 2017 to February 2018.

\begin{tabular}{|c|c|c|c|}
\hline Drug name & $\begin{array}{c}\text { Prophylaxis No of } \\
\text { patients N (\%) }\end{array}$ & $\begin{array}{c}\text { Treatment No of } \\
\text { patients N (\%) }\end{array}$ & Total N (\%) \\
\hline Ceftriaxone & $158(98.75 \%)$ & $83(96.5 \%)$ & $241(97.97)$ \\
\hline Ampicillin & $2(1.25 \%)$ & 0 & $2(0.81)$ \\
\hline Norflaxacillin & 0 & $3(3.5 \%)$ & $3(1.22)$ \\
\hline Total & $160(100 \%)$ & $86(100 \%)$ & $246(100)$ \\
\hline
\end{tabular}

Table 5: Single prescribed antibiotics for patients who undergone major surgery at NRH from February 2017 to February 2018.

\begin{tabular}{|c|c|c|c|}
\hline \multirow{6}{*}{ For prophylaxis } & Antibiotic combination & Frequency & $\begin{array}{l}\text { Percentage } \\
(\%)\end{array}$ \\
\hline & Ceftriaxone+Metronidazole & 39 & 57.4 \\
\hline & Ampicillin+Ceftriaxone & 5 & 7.4 \\
\hline & Metronidazole+Ampicillin & 13 & 19.1 \\
\hline & Ceftriaxone+cloxacillin & 11 & 16.2 \\
\hline & Total & 68 & 100 \\
\hline \multirow{7}{*}{ For treatment } & Ceftriaxone+Metronidazole & 106 & 76.8 \\
\hline & Metronidazole+Ampicillin & 5 & 3.6 \\
\hline & Ceftriaxone+cloxacillin & 11 & 8 \\
\hline & Ampicillin+Ceftriaxone & 3 & 2.2 \\
\hline & $\begin{array}{l}\text { Ampicillin+Ceftriaxone+Me } \\
\text { tronidazole }\end{array}$ & 2 & 1.45 \\
\hline & $\begin{array}{l}\text { Ampicillin+Gentamicin+Ce } \\
\text { phalexin }\end{array}$ & 11 & 8 \\
\hline & Total & 138 & 100 \\
\hline
\end{tabular}

Table 6: Combination of antibiotics used for prophylaxis and treatment for patients who undergone major surgery at NRH from February 2017 to February 2018.

\begin{tabular}{|c|c|c|c|}
\hline Class of antibiotic & For prophylaxis N (\%) & $\begin{array}{c}\text { For treatment } \\
\mathbf{N}(\%)\end{array}$ & Total (\%) \\
\hline Cephalosporin's & $213(72.45)$ & $217(56.81)$ & $430(63.61)$ \\
\hline Nitro imidazole & $51(17.35)$ & $113(29.58)$ & $164(24.26)$ \\
\hline Penicillin's & $30(10.2)$ & $35(9.16)$ & $65(9.62)$ \\
\hline Aminoglycosides & 0 & $14(3.66)$ & $14(2.07)$ \\
\hline Fluoroquinolones & 0 & $3(0.79)$ & $3(0.44)$ \\
\hline Total & $294(100)$ & $382(100)$ & $676(100)$ \\
\hline
\end{tabular}

Table 7: Class of antibiotic used for prophylaxis and treatments for patient who undergone major surgery in NRH from February 2017 to February 2018

patients, $11-20$ days for $21.9 \%$, and $>20$ days for $1.8 \%$. And Condition of discharge for patients who undergone major surgeries were $90.8 \%$ improved (Table 8).

This study indicate that duration of hospital stay was higher $(>11$ days) for $75.93 \%$ patients who receive antibiotics inappropriately. And also this study found that $10.5 \%$ of condition of discharge for patient who undergone major surgery was death, out of this $70.83 \%$ of patients has taken antibiotics inappropriately. Special attention needed to be given for patients with other comorbid conditions and taking other medications in addition to antibiotics (Table 8).

\section{Discussion}

This study identified that the prevalence of appendectomy was found to be $32.9 \%$, which has no more difference with study done in Italian general hospital (37.68\%). But prevalence of Cholecystectomy 


\begin{tabular}{|c|c|c|c|c|}
\hline \multirow{2}{*}{ No. } & \multirow{2}{*}{ Variables } & \multirow{2}{*}{$\begin{array}{c}\text { Frequency } \\
\mathbf{N}(\%)\end{array}$} & \multicolumn{2}{|c|}{$\begin{array}{c}\text { Inappropriateness of antibiotic } \\
\text { use }\end{array}$} \\
\hline & & & $\begin{array}{c}\text { For prophylaxis } \\
\mathrm{N}(\%)\end{array}$ & $\begin{array}{l}\text { For treatment } \\
\qquad \mathrm{N}(\%)\end{array}$ \\
\hline 1 & $\begin{array}{l}\text { Comorbid conditions } \\
\text { available }\end{array}$ & $83(36.4)$ & $27(32.5)$ & $42(50.6)$ \\
\hline 2 & Took Other medications & $75(32.9)$ & $26(34.7)$ & $39(52)$ \\
\hline \multirow{4}{*}{3} & Duration of Hospital stay & & & \\
\hline & $<10$ & $174(76.3)$ & $35(20.1)$ & $58(33.3)$ \\
\hline & Nov-20 & $50(21.9)$ & $26(52)$ & $39(78)$ \\
\hline & $>20$ & $4(1.8)$ & $2(50)$ & $2(50)$ \\
\hline \multirow{3}{*}{4} & Condition of discharge & & & \\
\hline & Improved & $204(89.5)$ & $54(26.5)$ & $82(40.2)$ \\
\hline & Died & $24(10.5)$ & $9(37.5)$ & $17(70.83)$ \\
\hline
\end{tabular}

Table 8: Medication and disease related factors cross tabulation with inappropriateness of antibiotic used for patients who undergone major surgery at NRH from February 2017 to February 2018.

was $5.3 \%$ which is very low than result of study in same hospital (Italian general hospital) (49.27\%) [8]. According to this study Benign prostate hyperplasia were $(20.2 \%)$ which was very different with study done in Department of Surgery, Rangpur Medical College Hospital, Rangpur, BPH which was (42\%) [19]. The reason for the difference could because the study done Rangpur Medical College Hospital mainly deals with study of major surgery associated with obstructive jaundice.

In this study the prevalence of inguinal hernia found to be $10.5 \%$ which was almost similar with the study done in a tertiary care teaching rural hospital in India (10.36\%) [16]. In this study the prevalence of genitourinary systems found to be $7 \%$ which had no more difference with the study done in secondary health-care level in the Kyrgyz republic (13.9\%) [20]. Out of 228 patients, small bowel obstruction was done for $23(10.1 \%)$ and large bowel obstruction 32 (14.0\%) which was very different with study done in Adama Hospital Medical College [21] small bowel obstruction (64 \%) and large bowel obstruction (36.0 \%).

In this study from the prescribed antibiotic drugs ceftriaxone was $52.88 \%$ for treatment which was different with study done in Navy Hospital, Jakarta, Indonesia $87.8 \%$ but, gentamycin use was similar in the same hospitals $3.66 \%$ and $3.7 \%$ respectively [13]. In this study (for treatment) the metronidazole prescribed were $(29.58 \%)$, cloxacillin (3.66\%), ampicillin (5.5\%) and gentamycin (3.66\%) When we compare with study done in Manipal Teaching Hospital, Pokhara, Nepal [12] the most commonly used individual antibiotics were preparation of ampicillin and cloxacillin (54.64) followed by metronidazole (31.95), ampicillin (18.34) and gentamicin (16.37), which was different but there is no more difference in case of metronidazole.

In current study the most prescribed antibiotic were ceftriaxone (71.96\%), Metronidazole (17.56\%) and ampicillin (6.76\%) for prophylaxis respectively which was different with study done in Orthopedics and Traumatology Surgical Unit of a Tertiary Care Teaching Hospital in Addis Ababa [22] the most frequently prescribed antimicrobial agent used for prophylaxis was ceftriaxone (70\%), cloxacillin (9\%) and Metronidazole (7\%) was used. However, ceftriaxone was almost similarly prescribed. The prophylactic antimicrobial regimens included both single as well as combination regimens; single regimens in prophylaxis took the lion's share. In this study the most commonly prescribed regimen among the combination regimens was ceftriaxone plus Metronidazole (57.4\%), and metronidazole plus ampicillin (19.1\%).

Combination of antibiotic are prescribed to reduce risk of wound infection and to prevent infection situation of a gross contamination. In this study the most prescribed combination antibiotic drugs for treatment were ceftriaxone plus Metronidazole 106 (76.8\%) followed by cloxacillin plus ceftriaxone $11(4.8 \%)$, ampicillin plus gentamycin plus cephalexin 11 (4.8\%), and ceftriaxone plus Metronidazole plus ampicillin $2(0.9 \%)$ which was very different with study done in Manipal Teaching Hospital, Pokhara, Nepal [23] the most commonly used antibiotic regimens were: ampicillin and cloxacillin combination preparation $(27.22 \%)$, ampicillin and cloxacillin combination along with metronidazole (5.13),ampicillin, metronidazole and gentamicin $(2.76 \%)$ and Metronidazole plus cloxacillin $(2.56 \%)$. The difference for antibiotic utilization could be because of difference on the type of common surgery in current study and the study done in Manipal Teaching Hospital.

The most common class of antibiotics used for patient who undergone major surgery for prophylaxis were cephalosporin 213 (31.51\%), followed by Nitro imidazole $51(7.54 \%)$ and penicillin 30 (4.44\%). Similarly a study done in Medicine surgical inpatient wards of Basaweswara Medical College Hospital [6] the most prescribed antibiotics were $3^{\text {rd }}$ Generation Cephalosporin's 108 (40.7\%), followed by Aminoglycoside 11 (4.2\%), Fluoroquinolones 11 (4.2\%), and Penicillin 9 (3.4\%).

The numbers of patients who were treated with monotherapy of antibiotic drugs for prophylaxis were $160(70.2 \%)$ and for the treatment $85(37.3 \%)$ and from antibiotic combinations, two drugs combination prescribed for prophylaxis were $68(29.8 \%)$, and for the treatment 130 (57.0\%) patients, and three drugs combination for treatment were prescribed 13 (5.7\%), which was different with study done in Medicine surgical inpatient wards of Basaweswara Medical College Hospital [6] which majority of them are on single antibiotics 73 (45.1\%), two antibiotics $75(46.3 \%)$ and three antibiotics $14(8.6 \%)$ for prophylaxis. The reason for the difference could be because of difference in study design as the study done in Basaweswara Medical College Hospital was a prospective study.

According to this study appropriately used antibiotic for prophylaxis were $72.37 \%$ which was very similar with study done in 21 public hospitals in Italy which were $72.6 \%$ [18]. This study also found that antibiotic therapy for treatment was inappropriate in $43.42 \%$ of patients. This finding was completely in agreement with the published data indicating that as many as $41 \%$ to $91 \%$ of all antibiotic prescriptions in hospitals are inappropriate [24]. Similar findings were also reported by another study from Brazil where rational antibiotic use was only $45.7 \%$ [25].

Limitation of this study was that the study design we used was retrospective study which is often subject to biases (errors that affect the observations of an investigation); for example, in the collection of data it is difficult to evaluate how the patients took their medication and if there is any unwanted effect of the drugs. Being retrospective study also made us not to study important variables including education level, adherence, patient-health worker communication and provider and health system related factors. Another limitation was the small sample size that we have used and that this study included only one referral hospital of the country.

\section{Conclusion}

Generally, this study indicated that underwent surgical procedures by majority of patients were appendectomy and benign prostate 
Citation: Wokuma TA, Dedefo MG (2018) Pattern of Antibiotics Use for Prophylaxis and Treatment among Patients Who Undergone Major Surgery at Nekemte Referral Hospital, West Ethiopia. J Bioanal Biomed 10:108-113. doi:10.4172/1948-593X.1000217

hyperplasia. Mostly prescribed antibiotics in the patients who undergone major surgery were ceftriaxone followed by Metronidazole. But since ceftriaxone is broad spectrum antibiotics it has higher chance to cause more drug resistant bacteria, thus we recommend the use cefazolin which is a first line agent for prophylaxis for most surgical cases. Additionally, the result of this study indicated some level of inappropriateness which high light need for intervention. The role of clinical pharmacist by studying the prescribing patterns was useful as it helps to assess if the right prophylactic therapy and postoperative treatment is being followed in the hospital.

\section{Acknowledgment}

We are thankful to Wollega University for their unreserved cooperation in making this study to be a fruitful work. We are also thankful for data collectors.

\section{Competing Interests}

No competing interests between authors.

\section{References}

1. Imranuddin M, Asfin M, Sruthi V, Deshpande S, Reddy MVR, et al. (2015) Cost analysis and prescribing patterns of antibiotics in postoperative surgery patients. Indo Am j pharm 5: 2231-6876.

2. Alavi SM, Roozbeh F, Behmanesh F, Alavi L (2014) Antibiotics use patterns for surgical prophylaxis site infection in different surgical wards of a teaching hospital in Ahvaz, Iran. Jundishapur J Microbiol 7: e12251.

3. Willems L, Simoen S, Laekeman G (2005) Follow up of antibiotic prophylaxis impact on compliance with guidelines and financial out comes $\mathrm{J}$ Hosp infect 60: $333-922$

4. Hoonk S, Hay J, Yook Y (2009) The efficacy of postoperative prophylactic antibiotics in orthognathic- surgery. Yoncei Med J 50: 55-59.

5. Stone HH, Haney BB, Zaura D, Eard K, Geheber E, et al. (1979) Prophylactic and preventive antibiotic Therapy, timing, duration, and economics. Ann surg 199: 691-698.

6. Dinesh R, Moulya MV, Siddiq A, Bharathi DR (2015) Evaluation of antibiotic usage as surgical prophylaxis in post-operative wards. Amer Jou of Pharm Tech Res 5: 435-443.

7. Anguzu JR, Olila D (2007) Drug sensitivity pattern of bacterial isolates from septic post-operative wound on a regional referral hospital Uganda. Afr Health sci 8: 148-154.

8. Martelli A, Mattioli FA (2000) Retrospective study showing the misuse of prophylactic antibiotics in patients undergoing appendectomy and cholecystectomy. Current Thera Res 61: 534-539.

9. Sekimuto M, Immaka Y, Evans E, Ishizaki T, Fukui T (2004) Practice variation in preoperative antibiotic use in japan. Intern Jou for Quality in Health Care 16: 367-373.
10. Mohagheghi MA, Mosavi A, Khatemi M (2005) Community based out patent practice of antibiotics use in Tehran. Pharm Epid Drug Saf 14: 135-138.

11. Yang SF, Nadimi S, Eggerstedt M, Thorpe E, Pittman A (2016) Antibiotic prophylaxis and postoperative wound infection rates in salvage surgery for head and neck cancer. Head Neck Cancer Res 1: 1-5.

12. Kumar NS, Varaprasad CP, Thyag A, Sudarsanan S, Reddy YH (2016) Prescribing pattern of antibiotics in surgical department in a tertiary care teaching hospital. World Jour of Pharma Res 5: 1138-1147.

13. Radji M, Aini F, Fauziyah S (2014) Evaluation of antibiotic prophylaxis administration at the orthopedic surgery clinic of tertiary hospital in Jakarta. Indonesia Asian Pac J Trop Dis 4: 190-193.

14. Rajeshwari, Nagabushan H (2016) Drug utilization study in postoperative patients in obstetrics and gynaecology ward of tertiary care hospital. Int J Basic Clin Pharmacol 5: 329-334.

15. Achong MR, Houser BA, Krusky JL (1977) Rational and irrational use of antibiotic in a canddian teaching hospital. Can med Assoc J 116: 256-259.

16. Chaudhary K, Panka J, Atul J, Arvind MK, Gaurav, et al. (2015) Usage of antimicrobials in post-operative patients in a tertiary care teaching rural hospital in India 2: 328-337.

17. Food, Medicine and Healthcare Administration and Control Authority of Ethiopia Standard Treatment Guidelines for General Hospital (3rd eds.) Ethiopia 2014: 13-20.

18. Testa M, Stillo M, Giacomelli S, Scofonne S, Zotti CM (2015) appropriate use of antimicrobial prophylaxis: un observasian study in 21 surgical wards of Public hospital 15: 63.

19. Roy BC, Hanifa A, Alam S, Naher S, Sarkar P (2015) Etiological spectrum of obstructive jaundice in a tertiary care. Global Jou of Med Res 4: 1-5.

20. Baktygul K, Marat B, Ashirali Z, Rashid H, Sakamoto J (2011) An assessment of antibiotics prescribed at the secondary health-care level in the Kyrgyz republic 73: $157-168$

21. Soressa U, Mamo A, Hiko D, Prevalence FN (2016) Causes and management outcome of intestinal obstruction in Adama Hospital, Ethiopia. BMC Surgery 16: 1-8.

22. Argaw NA, Shumbash KZ, Asfaw AA, Hawaze S (2017) Assessment of surgical antimicrobial prophylaxis in orthopaedics and traumatology surgical unit of a tertiary care teaching hospital in Addis Ababa. BMC Res Notes 10: 2-8.

23. Giri BR, Pant HP, Shankar PR, Sreeramareddy CT, Sen PK (2008) Surgical site infection and antibiotics use pattern in a tertiary care hospital in Nepal. JPMA 58: $148-151$

24. Hogerzeil HV (1995) Promoting rational prescribing: an international perspective. $\mathrm{Br} \mathrm{J}$ clin Pharmac 39: 1-6.

25. Fonseca LG, Conterno L (2004) Audit of antibiotic use in a Brazilian University Hospital. Braz J Infect Dis 8: 272-280. 